\title{
THE POLICY OF PROMOTION: THE CLASH OF RIGHTS IN SEX EDUCATION LAW
}

\author{
Martina Gillen, Lecturer in Law, University of Reading \\ INTRODUCTION
}

This paper briefly analyses the nature and impact of section 28 of the Local Government Act of 1988 (hereafter "Section 28") in England, Wales and Scotland; before looking at how sex education is governed in Northern Ireland. The central tenet of this paper is that in Northern Ireland there has been a failure to resolve the questions surrounding the practical need to discuss homosexuality in sex education. This issue may prove a complex and thorny one for the burgeoning human rights regime here since this area involves a number of competing rights, including:

- the rights of students to education and information;

- those of the gay community to equality under the law; and,

- those of parents and schools to have the curriculum taught in a manner harmonious with their religious and moral beliefs.

Another potential legal difficulty is the malleability and indeterminacy of the word "promote", which has been used to give Section 28 impact beyond its official scope, and may similarly obfuscate the level of quantifiable action required to comply with the equality provisions in section 75 of the Northern Ireland Act 1998. As a case study, the recent guidelines from the Scottish Parliament will be examined as an example of the work of a devolved government bound by equality provisions.

\section{Section 28: Its Implementation And Scope}

It is widely admitted that the introduction of Section 28 , which amended the Local Government Act of 1986, was a response on the part of the Conservative government of the time to the actions and attitudes of some Labour controlled local authorities. It was also a piece of legislation very much in keeping with the wider global trends in conservatism at that time. A notable parallel can be drawn between Section 28 and the Helms Amendment to the legislation governing the American National Endowment for the Arts (hereafter the "NEA"). The wording of the Helms Amendment and the wording of Section 28 are remarkably similar. The Helms Amendment to the NEA provided that, none of the funds authorized to be appropriated pursuant to that Act may be used to promote, disseminate, or produce obscene materials, including, but not limited to, depictions of sadomasochism, homo-eroticism, the exploitation of children or any individual engaged in sex acts. Section 28 reads as follows:

“(1) A local authority shall not intentionally promote homosexuality or publish material with the intention of promoting homosexuality; promote the teaching in any maintained school of the acceptability of homosexuality as a pretended family relationship. 
(2) Nothing in subsection (1) shall be taken to prohibit the doing of anything for the purpose of treating or preventing the spread of disease."

As Stychin notes the Helms Amendment was largely a knee-jerk response to the emergent gay and lesbian arts culture, and especially the work of gay artists notably, Robert Mapplethorpe and Andres Serrano, which was considered unacceptable and pornographic. ${ }^{1}$ This 'knee-jerk' reaction was not a uniquely American phenomenon and Section 28 is evidence of the desire of some sections of the British government of the time to limit the emergent gay cultural scene by choking off its funding and support from the more liberal local authorities. It is perhaps this fact, coupled with the ambiguity of Section 28's approach to schools, which has allowed both supporters and detractors alike to claim at various times that Section 28 does not concern schools. Indeed, a spokesperson for the Department of Education went so far as to assert to the media during the discussion surrounding the government's recent attempts to repeal Section 28 that:

"Section 28 does not apply, and never has applied, to the activities of individual schools in England. It applies only to the activities of local authorities. But it is clear that it has caused much confusion and many teachers believe that it does apply to schools." 2

Nevertheless, every debate concerning Section 28 or its equivalents has centred around schooling, and the figure of the child, innocent, vulnerable and in need of protection has become totemic for all sides in this perplexing debate. Furthermore, the homosexual has taken on a totemic role in this debate. For the proponents of Section 28 the homosexual is not only the permissive ally and seducer of the left wing but also the dangerous infectious recruiting pervert who preys upon children. There is a conflation of the homosexual with the paedophile. At its most extreme, and violent, this attitude may be illustrated by the comments of one Leader of the South Staffordshire County Council:

"Those bunch of queers that legalise filth in homosexuality have a lot to answer for. I hope they are proud of what they have done ... It is disgusting and diabolical. As a cure I would put 90 per cent of queers in the ruddy gas chamber. I would shoot them all. Are we to keep letting these queers trade their filth up and down the country? We must find a way of stopping these gays going round." 3

Compare this to the comments of Baroness Knight of Collingtree, one of the original supporters of Section 28, during the second reading of the government's proposed bill to repeal that clause:

"I referred earlier to the noble Lord, Lord Haringey. Haringey council made a video called "How to become a lesbian in 35

1 Stychin, Law's Desire: Sexuality and the Limits of Justice, (1995), p 14.

2 Available online at:

http://news.bbc.co.uk/hi/english/education/newsid_689000/689288.stm.

3 Kaufmann and Lincoln, High Risk Lives, Lesbians and Gay Politics after the Clause, (1991), p 4. 
minutes". It was intended to be shown in a school for mentally handicapped girls, some of whom were extremely young. In the course of my years as a local councillor I took a great interest in the mentally handicapped children in my area; I served on the board of schools and had a great deal to do with them. From my experience of those children, it is difficult enough for them to understand normal sexual relations without having homosexuality foisted upon them. I find it horrifying that anyone would support that. All of that was stopped dead by Clause 28. Clause 28 was introduced for that purpose and that purpose alone." 4

Although Baroness Knight was undoubtedly well intentioned, her comments are disturbing because not only are they factually inaccurate as Lord Harris of Haringey pointed out in a later debate ${ }^{5}$ but they retrench the notion of the homosexual as predator, and homosexuality as something abnormal and infectious. Homosexual relations are not the natural expression of adult homoerotic desire and bonds of love but rather something abnormal to be "foisted" upon children. The Baroness does go on to clarify that she has no wish to marginalize or be unfair to those who "choose" a homosexual way of life. However, the notion of choice, of choosing a homosexual lifestyle, is itself a contentious and divisive issue, not least because the notion that homosexuality is chosen buttresses the idea that it can be "foisted" upon the innocent and unwary.

In sharp contrast to this image is the image of the homosexual as a member of a persecuted minority. Those in favour of repeal often argue from the perspective of protecting children from homophobic bullying and giving them proper advice about the difficult issue of sexual orientation, or from the perspective of removing the inherently discriminating legislation from the statute books. In either scenario, the homosexual is characterised as victim, as outsider. Either role ultimately pushes the reality of gay life to the margins and replaces it with an image acceptable to the majority heterosexual community thus dis-empowering the gay subject. Gays and lesbians are forced to be either passive victims in need of legal protection and the patronage of the concerned liberal majority or vilified as criminals. Either position robs them of status and control over their own lives because it describes and identifies them solely in relation to how the heterosexual world chooses to view them.

Schooling and in particular sex education has thus become the arena for an intense political and moral struggle.

\section{The Impact of Section 28}

One of the major sources of contention during the recent repeal debate was the efficacy and scope of Section 28. There are essentially two approaches to the impact of Section 28. The first is to assert that, since no litigation has ever arisen Section 28 has not impacted upon the actions of schools or other bodies. The other is to assert that it has been an effective barrier to schools

4 Hansard, $6^{\text {th }}$ December, 1999, col 1103.

5 Hansard, $7^{\text {th }}$ February, 2000, col 474. 
and authorities disseminating material discussing homosexuality. Some view this as a positive development. Lord Moran for example quoted the following letter he had received from a schools inspector:

"Section 28 greatly strengthens the hand of officers. If they have a proposal before them from a Council committee which clearly promotes homosexuality then if reason and common sense fail the officer can appeal to Section 28. Councillors know that officers cannot be made to act against the legal advice they have received." 6

Others view this restriction as pernicious and damaging:

"Perhaps I may record a few of the facts of life, if I can use those words. The first facts are legal facts. Section 28 is probably one of the worst drafted clauses on our statute book. Reference has been made to how badly the Section is drafted and the fact that the word "promote" is subject to a wide range of interpretations, and how that has led to some of the difficulties in discussing this issue. The other part of Section 28 refers to "pretended family relationships". Those, too, are not the words of calm parliamentary draftsmen. Those are the words used by those in the saloon bars in the Home Counties. It has nothing to do with precision in legislation. It is the kind of terminology used by two middle-aged gentlemen in florid ties who with one breath claim that they have never met a homosexual since they left boarding school and in the other claim that the BBC is absolutely crawling with them."'

Certainly, the academic literature cites a number of instances where local authorities have withdrawn or refused funding for projects on the basis of potential Section 28 liability. Edwards notes a number of instances notably the example of a head teacher cancelling a performance in a secondary school of the play "Trapped in Time" because the drama contains a scene in which a male character "comes out" as gay because it was feared such a scene was in contravention of Section $28 .^{8}$ Indeed, in the House of Lords debate one peer noted that:

"I even heard of someone leaving a maintained comprehensive school six years ago who had taught Shakespeare at A-level and had been told that it was impossible to discuss any question of a homosexual relationship in regard to Shakespeare's work. How the Sonnets can be discussed without that question being considered is beyond me. That teacher was told that Section 28 prohibited such discussion."9

Clearly, the key impact of Section 28 is not merely the practical import that its framers intended but also its symbolic significance, which has extended its shadow far beyond the arena of the local authority. As one peer (Earl Russell) astutely noted:

6 Hansard, $7^{\text {th }}$ February 2000, col 413.

7 Lord Whitty, Hansard, $7^{\text {th }}$ February 2000, col 477.

8 Edwards, Sex and Gender in the Legal Process, (1996), p 75

9 Earl Russell, Hansard, $7^{\text {th }}$ February 2000, col 422. 
"If one believes, as I do, that most people do not have a choice about their sexual orientation, one must believe that, whatever is their sexual orientation, they should make as good a job of living that way as they possibly can. If one is to do that, one must be entitled to the respect of being an equal citizen - equal before the law and equal in moral esteem. If one is to be denied that, one finds that life is very difficult indeed. Precisely what annoys most homosexuals about the section is that they see it as being a badge of inequality." 10

It is this fostering of a sense of division and difference between the homosexual and heterosexual members of the community which may prove the undoing of Section 28.

\section{Section 28 And Its Impact Upon The Official Guidance On Homosexuality}

Regardless of the actual legal impact of Section 28, there has been an evident sea change in Government policy during its lifetime. This is clearly indicated by official guidance circulars. Circular 11/87 made no attempt to proscribe coverage of homosexuality in sex education, but did advise schools that such coverage may cause offence. Furthermore, it stated that:

"There is no place in any school for teaching which advocates homosexual behaviour, which presents it as a norm, or which encourages homosexual experimentation by pupils."11

The 1994 Circular (5/94) contains no specific reference to homosexuality beyond reasserting the legal position as regards Section 28. The only possible sign of governmental relent may be found in paragraph 8 , which stresses the need for teachers to acknowledge that whilst sex education should be taught in the context of heterosexual marriage and reproduction, many children come from very different backgrounds and therefore efforts should be made to avoid 'causing hurt and offence. . . and to allow such children to feel a sense of worth.' This is undoubtedly a sop to the much more fearsome Cerberus of common-law partners and single parent families than any attempt to assuage the alienation of the gay community. Despite this sanguine repetition of, and reliance upon, Section 28 there are some inherent problems with its approach.

\section{Section 28: The Areas Of Legal Contention}

There are two major legal difficulties with the interpretation and implementation of Section 28. The first is the ambiguity of the word "promote" and the second is that Section 28 is on a collision course with the blossoming human rights culture prevalent in Europe today. There is strong legal precedent to indicate that the test for "promoting" something is a stringent one with a high threshold. As Thomas and Costigan ${ }^{12}$ have noted

10 Hansard, $7^{\text {th }}$ February 2000, col 421.

11 DES 1987, para 22.

12 Thomas and Costigan, Promoting Homosexuality, Section 28 of the Local Government Act 1988, (1990), p 11. 
the Gillick $^{13}$ case seems to be authority for suggesting that to make something easier is not necessarily to promote or encourage it. This difficulty of interpretation was recognised during the House of Lords debate on clause 28 (as it then was). Lord Falkland remarked:

"It is just not possible (and I dare say we shall argue the point) to understand what is meant by the word 'promote' . .."14

The Minister replied to that comment with an explanation that might have proven key had any litigation tested the meaning using the rule in Pepper $\mathrm{v}$ Hart. ${ }^{15}$

"But we think that "promote" has a clear meaning. If one promotes something, one is deliberately doing something to give what is promoted a more favourable treatment, a more favourable status or wider acceptance, than other things or that thing hitherto."16

This explanation did little to clarify the meaning of "promote" and potentially opened up local authorities to a broad liability for any new project or funding for a homosexual cultural group or for any educative purposes with any content concerning homosexuality whatsoever. Thus the fundamental subjectivity of the concept of promotion remains.

Lord Lester highlighted the second difficulty concerning the drafting of Section 28 during the repeal debate. ${ }^{17}$ He drew the House's attention to the European Court of Human Rights decision in the case of Sagueiro da Silva v Portugal. ${ }^{18}$ In that case the Court ruled that the refusal to grant custody of a child to the father during divorce proceedings simply on the basis of his being in a homosexual relationship was contrary to his rights under Article 14, read with Article 8, of the ECHR and amounted to unjustifiable discrimination. Thus, homosexual relations based on love and affection and long-term commitment have been recognised as capable of constituting real family relationships. Section 28, with its assertion that homosexual relationships are not and must not be treated as such by local authorities, flies in the face of the Convention. Furthermore, Section 28 must also be viewed as an interference with free speech and an unjustifiable act of discrimination against homosexuals. Lord Lester warns that although it is legitimate to protect children from immoral or harmful influences, Section 28 may not have been drafted conservatively enough to stay within these bounds of legitimate action.

Despite these warnings, the repeal of Section 28 was rejected by the Lords and the government declined to push the Bill any further within that legislative session. The issues therefore remain unresolved although the legal position is clear since Section 28 is still firmly in place in England and Wales. This may be illustrated by the governments' recent sex education guidelines. On the topic of the nature of relationships, the guidance is that:

13 Gillick v West Norfolk and Wisbech Area Health Authority [1986] AC 112.

14 Hansard, $1^{\text {st }}$ February, 1988, col 867.

15 Pepper v Hart [1993] A.C. 593

16 Lord Caithness, Hansard, $1^{\text {st }}$ February, 1988, col 890.

17 Hansard, $7^{\text {th }}$ February, 2000, col 465.

18 REF00001264 12/12/99 
"Within the context of talking about relationships, children should be taught about the nature of marriage and its importance for family life and the bringing up of children. The Government recognizes that there are strong and mutually supportive relationships outside of marriage. Therefore, children should learn the significance of marriage and stable relationships as key building blocks of community and society. Teaching in this area needs to be sensitive so as not to stigmatise children on the basis of their home circumstances." 19

Thus, the Government has attempted to temper the stringencies of Section 28 with recognition of relationships outside of marriage although this may also be read as referring to single heterosexual parents as well as gay parents. The question, however, cannot remain in stasis long because of the issue of European rights involved. It is at this point that we shall turn to Northern Ireland, a jurisdiction with a tabula rasa in relation to legislation like Section 28 , but with equally a well-known connection between its schools and the various churches of Northern Ireland, which has nurtured a laissez faire attitude toward sex education. How can this jurisdiction cope with the demands of its new devolved rights culture?

\section{Sex Education in Northern Ireland: the impact of Section 75}

Historically, Northern Ireland's education system has been inseparable from its religious life. As Lundy has noted:

". . . the most distinctive factor about Northern Ireland's school system is that it is de facto although not necessarily de iure religiously segregated." 20

This division is entrenched by the administrative system for schools in Northern Ireland. On the one hand are voluntary schools which are almost overwhelmingly Catholic in their ethos, and thus, predominantly fall under the control of the Council for Catholic Maintained Schools, and on the other are controlled schools which were Protestant church schools which transferred their assets and obligations to the Government for funding in exchange for guaranteed places on schools' governing boards. This arrangement means that with a few rare exceptions, the relevant church holds a majority of the places on the board of governors of any school in Northern Ireland. Furthermore, because of a wide degree of satisfaction with Northern Ireland's academic achievements among their constituents, politicians are reluctant to interfere with the current schools system.

However, the influence of the churches and the general conservative tenor of Northern Irish society has meant that in the area of sex education there has been little or no guidance in recent years. DENI Circular 1987/45 provides that sex education should be taught in all schools but " in a sensitive manner which is in harmony with the ethos of the school or college and in

19 Department for Education, Sex and Relationship Education Guidance, Document Reference Number DfEE 0116/2000, s 1.21.

20 Lundy, Education Law, Policy and Practice in Northern Ireland, (2000), p 6. 
conformity with the moral and religious principles held by parents and school management authorities." 21

Many of the main Christian denominations are of the view that homosexuality is sinful and abhorrent. Indeed, in the Papal encyclical Veritatas Splendor, His Holiness asserted that acts of sexual perversion are acts that are intrinsically evil and this means that whatever the circumstances they are not capable of being ordered to God or to the good of the person involved. ${ }^{22}$ This notion of disorder was precisely the protest His Holiness made against a Gay Pride Parade in Rome in 2000 on which occasion he gave a short speech reasserting that the Catholic view on homosexuality is that it is intrinsically evil..$^{23}$

The Catholic Church is not alone in this attitude as many Protestant denominations also hold that the Bible enjoins us to view homosexuality as a grave and terrible sin. Prior to devolution, article 8 of the Education Reform (NI) Order 1989 was to be balanced against the guidance from DENI that "schools and colleges cannot ignore consideration of sexual practices which run counter to the moral standards of society in Northern Ireland". However as Lundy has noted:

"The influence of the churches on the schools system and the moral tenor of society in Northern Ireland is such that it is unlikely that a school or even an individual teacher would provide sex education that was anything other than suitably moral. It is almost inconceivable that schools would promote homosexuality or even sex outside marriage." ${ }^{24}$

How then will this situation be effected by the limitations placed on local authorities (including the Education and Library Boards which manage schools) under section 75 of the Northern Ireland Act 1998 (hereafter "Section 75")?

"75. - (1) A public authority shall in carrying out its functions relating to Northern Ireland have due regard to the need to promote equality of opportunity -

between persons of different religious belief, political opinion, racial group, age, marital status or sexual orientation;

between men and women generally;

between persons with a disability and persons without; and

between persons with dependants and persons without."

Again we must note the use of the word "promote" which has still not been satisfactorily defined and is further confused by the addition of "having due regard". We have already seen from the debate on Section 28 that "promote" is a contentious and ambiguous word. Furthermore, the rights enshrined in the ECHR are also part of the foundation of the new Northern Ireland

21 Education Reform (NI) Order 1989 art 8(2).

22 His Holiness Pope John Paul the Second, Veritatis Splendor, 1993.

23 An account of His Holiness' Speech can be found at: http://news.bbc.co.uk/hi/english/world/europe/newsid_825000/825852.stm.

24 Lundy, Education Law, Policy and Practice in Northern Ireland, (2000), p 143. 
government, which is constrained in its legislative competence to adhere to its principles. ${ }^{25}$ There is an almost immediate conflict of rights apparent then in this issue arising from the competing rights entailed in the ECHR.

The first and in this issue central right is that enshrined in Article 2 of the First Protocol of the ECHR, the right to education. It is essential that this be read in conjunction with the United Nations Convention on the Rights of the Child (hereafter the "CRC"), also because the right to education raises two important issues. Article 2 asserts that no one should be denied the right to education and that the state should respect the right of parents to ensure education and teaching in conformity with their own religious and philosophical convictions. This must be read in conjunction with the provisions of the CRC. The United Kingdom's obligations under the CRC have been described as enshrining the four Ps: participation by children in decisions about their lives, protection of children from abuse and neglect, the prevention of harm to children, and provision to meet their basic needs. While the desires of parents and children are usually harmonious, what would happen if a gay child wished to receive appropriate information and instruction on homosexual relationships within the broader context of general sex education, but the parents felt that that type of education or indeed any type of sex education was inappropriate? As it currently stands, the situation in Northern Ireland is unclear because in practice it is rarely tested. One piece of case law, which is perhaps pertinent, is the case of Kjeldsen, Busk, Masden and Pedersen. ${ }^{26}$ In that case parents with strong Christian beliefs objected to compulsory sex education lessons in Danish state schools and challenged the policy before the Court. In affirming that Article 2 of Protocol No. 1 enjoined the state to respect parents' religious and philosophical convictions in their children's education, the Court explained that the state is obligated to ensure the communication of information and knowledge in an objective and pluralistic manner. States are not allowed to seek to indoctrinate. However, the sex education lessons, which the legislation had intended to be imparted to pupils, did not amount to indoctrination or advocacy of a specific kind of sexual behaviour. This raises some interesting issues as to whether this can be applied negatively? Can failure to deal with homosexuality amount to heterosexual indoctrination? Or does existing practice, though respectful of parents, contravene this prohibition? Is this case really a charter for parent's rights since it is unlikely that an educational programme could be considered indoctrination?

There is certainly a substantial body of parental opinion in Northern Ireland that is against the inclusion of homosexual issues within the sex education curriculum. A Health Promotion Agency survey has indicated that $2 \%$ of parents feel any sex education is inappropriate to the degree that they would withdraw their children from sex education lessons and $21 \%$ feel any sex education which includes any homosexual content is inappropriate and should not be taught in schools. ${ }^{27}$ Despite this, there is no statutory right for parents to withdraw their children from sex education although in practical

25 Northern Ireland Act 1998 s 42(2).

26 REF00000094 07/12/76

27 The Health Promotion Agency for Northern Ireland, Sex education in Northern Ireland, Views from Parents and Schools, (1996), pp 35 and 25. 
terms most schools still require consent. However, it would be better if a clear legislative statement were made as to the rights of parents and children in this area. In England and Wales, the provision of sex education is mandatory for all schools but parents have a right to withdraw their children. This however may be in contravention of the CRC because the child is not consulted. There are a number of suggested solutions but none has satisfactorily balanced the need for safe sex education for the modern world dealing with the crisis of Aids, and the need to respect both parents and children. In Northern Ireland this may be exacerbated by the presence of devolved legislative bodies. The Westminster Government could formulate policy and then face any challenges that may arise from the Human Rights Act or the ECHR, because it is a sovereign body and not constrained in its legislative powers. The Northern Ireland Assembly is prohibited from making such legislation in the first place because its devolved nature makes creating legislation in breach of the ECHR ultra vires. It might also be difficult to formulate a policy that could not be construed as discriminating against a particular religious grouping. Any discussion of the difficult issues of abortion, contraception or homosexuality, could be viewed as discriminating against Catholics whose religion forbids such practices, while a failure to touch upon such topics could discriminate against some of the Protestant denominations or indeed humanists and agnostics who labour under no such prohibition.

The second issue is the right of homosexuals to equality before the law. This is not only suggested by the "promotion of equality" provisions of Section 75 , but is also contained within the ECHR in that under Article 14 the rights and freedoms set forth in the Convention shall be secured without discrimination on any ground. Certainly, the right to education and the right to freedom of expression, and freedom of thought, conscience and religion are impinged upon if the gay community is not permitted to have sex education on an equal footing with their heterosexual counterparts. Although the right to freedom of expression is limited and expressly includes provision for the protection of public morals, the other rights are not. There is, of course, the question of margin of appreciation in the implementation of the ECHR provisions and indeed the need to clarify what the term "promote equality" in Section 75 actually means. For the most part, these practical decisions and policy formulations will rest in the hands of the Northern Ireland Human Rights Commission (hereafter the "NIHRC"). However, the recent NIHRC report on "Enhancing The Rights Of Lesbian, Gay And Bisexual People In Northern Ireland," is decidedly muted upon this issue, merely noting that although there is no formal legal requirement to provide sex education in Northern Ireland, failure to do so may be a breach of the requirement under the Education Reform (Northern Ireland) Order 1989 that schools' curricula prepare pupils for the "responsibilities and experiences of adult life". ${ }^{28}$

However Northern Ireland, is not the only devolved government wrestling with these issues. Scotland has recently repealed its equivalent of Section 28 and is setting about formulating its own sex education policy within a human rights framework.

28 Art 4. 


\section{The Scottish Model: A Case Study In The Policy of A Devolved Government}

The Scottish Parliament has opted for an informal arrangement embedded within a strong rights framework. The guidelines assert quite clearly that the specific content of the sex education curriculum will not be laid out by government policy and that the responsibility for sex education delivery rests with education authorities and school managers. However they have also been equally clear that the Executive Education Department has, after consultation, drawn up guidelines to ensure that sex education has a secure place within the curriculum. Section 56 of the Standards in Scotland's Schools Act 2000 is explicit in asserting that because the Minister issues guidelines a schools actions may be open to challenge if it is found that they do not follow them and are acting unreasonably in doing so.

The thrust of this advice to school authorities is that sex education is best planned and delivered within a wider health education programme and as part of a programme of religious and moral education.

The recently published Scottish Guidance on Sex Education makes some attempt to deal with a number of the problematic issues already discussed. The first is an explicit acknowledgement of the rights and responsibilities implied by law in this context:

"The right of the child to education.

The right of the young person to have their views increasingly taken into account as they mature.

The right of pupils to have their views taken onto account when the school is preparing its development plan.

The right of parents to have their religious or philosophical convictions taken into account, within specified limits.

The responsibility of parents to provide their child with efficient education.

The responsibility of the local authority to secure provision of education that takes into account the development of the personality, talents and full potential of the child (this means a statutory duty to consider each child individually).

The responsibility of schools to consult with parents on programmes for sex education."

This clear statement, supported by a structure of legislation in the form of the Standards in Scotland's Schools Act 2000, solves many difficulties highlighted in the Northern Ireland model.

With regard to the parents' right to withdraw their child, they have that right but are advised to discuss the matter with the head teacher. Sex education in this scheme is treated as a matter of general personal development and has many of its elements holistically scattered throughout the curriculum to provide a grounded moral social and emotionally secure learning context. The parent's actions are not permitted to prevent the child from receiving an efficient education. Furthermore, the Children (Scotland) Act 1995 requires authorities to educate the child with regard to the parent's religious and philosophical beliefs although the child's welfare is paramount. The 1995 
Act also requires authorities to give regard to children's views in line with their age and maturity. This provision also requires a subtle change in the role of the parents once a child reaches the age of sixteen: the parents then cease to give directions to children but instead offer them guidance. This provision may prove invaluable when dealing with a conflict of rights between the needs of the child and the wishes of the parent.

The repeal of Section 28 does not appear to have caused Scotland to fall into moral decline. Rather the emphasis is on a partnership between parents and schools to educate children in how to have responsible self affirming and supportive relationships in a stable and committed (preferably marital) context while fostering tolerance and understanding of those whose backgrounds and desires differ. There is also provision for those of different religious beliefs to foster this kind of understanding in a manner that is appropriate to their belief structures. Denominational schools are expressly permitted to draw up their own guidelines. A vital element in the ethos building is that:

"Pupils should be encouraged to appreciate the value of stable life, parental responsibility and family relationships in bringing up children and offering them security, stability and happiness. Pupils should also be encouraged to appreciate the value of commitment in relationships and partnerships including the value placed on marriage by religious groups and others in Scottish society. At the same time teachers, must respect and avoid causing hurt or offence to those who come from backgrounds that do not reflect this value. All pupils should be encouraged to understand the importance of self-restraint, dignity, respect for themselves and the views of others." 29

This broad policy statement is a good beginning towards equality in sex education since the emphasis is placed on the quality and emotional commitment of the relationships involved. Although marriage is to be discussed and valued, so also are other relationships. This seems to be an excellent compromise to the clash of interests between religious groupings and the gay community. It is of course yet to be seen what the denominational schools will do within this framework. However, the protections concerning the need to meet the needs of the individual child, and to respect the wishes of the parents, may well do much to prevent any serious rights abuses occurring, either to those who wish to receive education different from the spiritual ethos of their institution, or to those who wish to provide educational establishments who act in harmony with their spiritual beliefs. However, the question is still unresolved as to the potentiality that fostering an atmosphere where certain types of sexual desire and action which are legal and permissible in the state are vilified might not in itself in some extreme cases constitute an abuse of rights, especially if such teaching directly led to a hate crime. How responsible a teacher or preacher would be for the actions of those who acted upon their anti-gay rhetoric, is a question admitting of no clear answer.

29 Scottish Executive Department of Education Circular 2/2001 


\section{CONCLUSIONS}

Sex education concerns some of the most fundamental principles and values of our society. It also involves the needs of one of our most precious and vulnerable groups, our children. Because of this we have a most pressing and urgent need to clarify our policies, particularly on clashes of rights, so that the best interests of our children may be served. Thus far both the NIHRC and the Assembly have failed to provide guidance on this crucial matter. The rights asserted by Section 75 do not of themselves solve any of the contentious issues surrounding this topic. A flexible framework of guidance as in the Scottish model may be the answer although any solution must deal with the clash of rights within the social context of Northern Ireland. To conclude, the words of the Quaker Representative Bronwen Currie to the Scottish Equal Opportunities Committee during the Section 28 repeal debate, may be quoted:

"Education is about preparing children and young people to live in a plural society.

Our education policy needs to prepare them for that society by developing clear policies on sexual education and the conflict of rights." ${ }^{30}$

30 Scottish Parliament Equal Opportunities Official Report, Meeting 6, 2000, available online at http://www.scottish.parliament.uk/official_report/cttee/equal00/eo00-0602.htm. 